\title{
IMPROVING THE RHEOLOGICAL AND FLUID LOSS PROPERTIES OF THE WATER-BASED MUD USING WHEAT FLOUR
}

\author{
Hani Ali AL Khalaf \\ PhD student, Department of Petroleum Engineering, Faculty of Earth Science, University of Miskolc \\ 3515 Miskolc, Miskolc-Egyetemváros, e-mail: oljhani@uni-miskolc.hu \\ Zeeshan Ahmad \\ MSc student, Department of Petroleum Engineering, Faculty of Earth Science, University of Miskolc \\ 3515 Miskolc, Miskolc-Egyetemváros, e-mail: zeeshan.pakturk@uni-miskolc.hu
}

Gabriella Kovácsné Federer

PhD associate professor, Department of Petroleum Engineering, Faculty of Earth Science, University of Miskolc 3515 Miskolc, Miskolc-Egyetemváros, e-mail: g.federer@uni-miskolc.hu

\begin{abstract}
This study aims to evaluate the effect of wheat flour as a natural and environmentally friendly material on the properties of water-based mud. Recently, many experiments have been conducted with various additives to improve the properties of drilling fluids. The effect of using wheat flour as a new additive to drilling fluid was studied to improve rheological and filtration properties. In the laboratory several samples of water-based mud were prepared, different concentrations of wheat flour from 1 wt $\%$ to 7 wt \% were added to the mud and tested by using a Fann 35 viscometer, 140 Fann Mud balance, and an API LT-LP filter press. The results showed that adding $7 \mathrm{wt} \%$ of wheat flour was the optimal concentration. It was found that the apparent viscosity and yield point increased by 50\% and 35\%, respectively, when $7 \mathrm{wt} \%$ of wheat flour was added to the water-based drilling fluid. Likewise, the fluid loss rate was reduced by $25 \%$ when using the same concentration of wheat flour.
\end{abstract}

Keywords: water-based mud, wheat flour, rheological properties, fluid loss, environment friendly.

\section{Introduction}

Oil is considered one of the most in-demand commodities in the world because it is a raw material in many industrial fields. Therefore, improvements in exploration and drilling operations are still going on in order to hit new sources of oil. The drilling of oil wells is one of the most expensive and complex operations that require suitable planning [1]. Careful selection of the elements of the drilling operations plays a vital role in the optimum operation. Specifically, the drilling fluid selection is the most important element in the drilling operation. The flow of drilling fluid inside the well is similar to the blood flow in our bodies. The selection of drilling fluid depends on numbers of factors such as cost, environmental impact, mineralogical composition of clays, formation temperature, the degree of compaction and pore pressure, etc. A single drilling fluid system is not always suitable or may not perform well in all areas. Therefore, the mud system should be properly designed on the basis of the geology of the area, subsurface stresses, pore pressure gradient, water contact in the rocks and laboratory tests [2,4]. water-based mud is the most commonly used system to drill wells because water-based mud is environment-friendly and less expensive. Oil-based fluids have higher costs and are used in the sections where there is a chance of pipe sticking or well instability such as salt and shale sections. A drilling bit in combination 
with drilling fluid facilitates processes such as an increase in the rate of penetration by removal of cuttings, decrease in bit wear and tearing by cooling. Drilling fluid maintains the stability of the wellbore and prevents collapse by the usage of a suitable weight of drilling fluid [3].

Numerous chemicals, natural materials, and different types of polymers have been used in the preparation of drilling fluid to meet different drilling fluid requirements such as density, rheology, fluid loss control, etc $[5,6,7]$. From the study, it was found that wheat flour can be one of the most important additives for drilling fluid because it has a positive effect on viscosity and reduces fluid loss. Wheat flour is classified as an inexpensive and environmentally friendly material. Huge quantities of wheat are produced in the world annually over 700 million tons. There are no previous studies on using wheat flour directly as an additive to drilling fluid, but wheat starch has been used in much research. Wheat flour consists of 70-73\% starch and between $8-14.5 \%$ protein [6]. R. Iqbal et al. [5] investigated the utilization of wheat starch in a water-based mud system. They found that wheat starch shows improvement in the rheology of the drilling fluid. Ghazali et al. found that starch will plug the small pores in the filter cake to decrease the potential of fluid loss inside the formation [8]. O Mojeed et al. found through research that the use of cassava flour increases the viscosity and the density of the drilling fluid [9].

In the study, experiments are carried out to formulate a water-based mud system with different concentration of wheat flour. The utilization of wheat flour in a water-based mud system and measure apparent viscosity, plastic viscosity, yield point, gel strength, Fluid loss volume and filter cake thickness of the drilling fluid at normal pressure and room temperature. To our best knowledge, this is the first study that uses wheat flour as an additive to the water-based drilling fluid.

\section{Methodology and Experimentation}

In this study, the American Petroleum Institute standard API-RP-13B was used to conduct all tests. Figure 1 shows the experimental workflow of the study process.

\subsection{Materials}

Wheat flour is the main material used as an additive in the study which is available in local markets. The particle size of wheat flours ranging from 358 to $17 \mu \mathrm{m}$. It was added to the drilling fluid as an additive in certain proportions ( $1 \mathrm{wt} \%, 3 \mathrm{wt} \%, 5 \mathrm{wt} \%$, and $7 \mathrm{wt} \%)$. Wheat flour is added to the drilling fluid that was prepared from bentonite and water.

\subsection{Preparation of water-based mud}

This study is conducted on one system of drilling fluid mainly consisted of bentonite and water and wheat flour additive added in different proportions. Five samples of drilling fluid were prepared for the experiments. Each sample was prepared from $350 \mathrm{ml}$ of fresh water and $22.5 \mathrm{gr}$ of bentonite. Firstly, water was poured into the Hamilton Beach mixer, and bentonite was added gradually during the running of the mixer, then stirring the mixture for 20 minutes to achieve complete homogeneity. After the mixing process, the mixture was left for 24 hours to ensure the hydration of the bentonite before using it in experiments. After that, experiments were conducted to measure the rheological and fluid loss properties on the drilling fluid sample without adding wheat flour and it was considered as a reference sample in this study. Afterwards, the planned proportions of wheat flour were added to the remaining four samples of drilling fluid ( $1 \mathrm{wt} \%, 3 \mathrm{wt} \%, 5 \mathrm{wt} \%$, and $7 \mathrm{wt} \%)$ in succession and the mixture was mixed for 10 minutes by a Hamilton mixer until homogeneity. Thereafter, rheology tests (apparent viscosity, plastic 
viscosity, and gel strength), a density test, a fluid loss test were performed, and then the results of these tests were analysed to determine the optimal concentration of wheat flour.

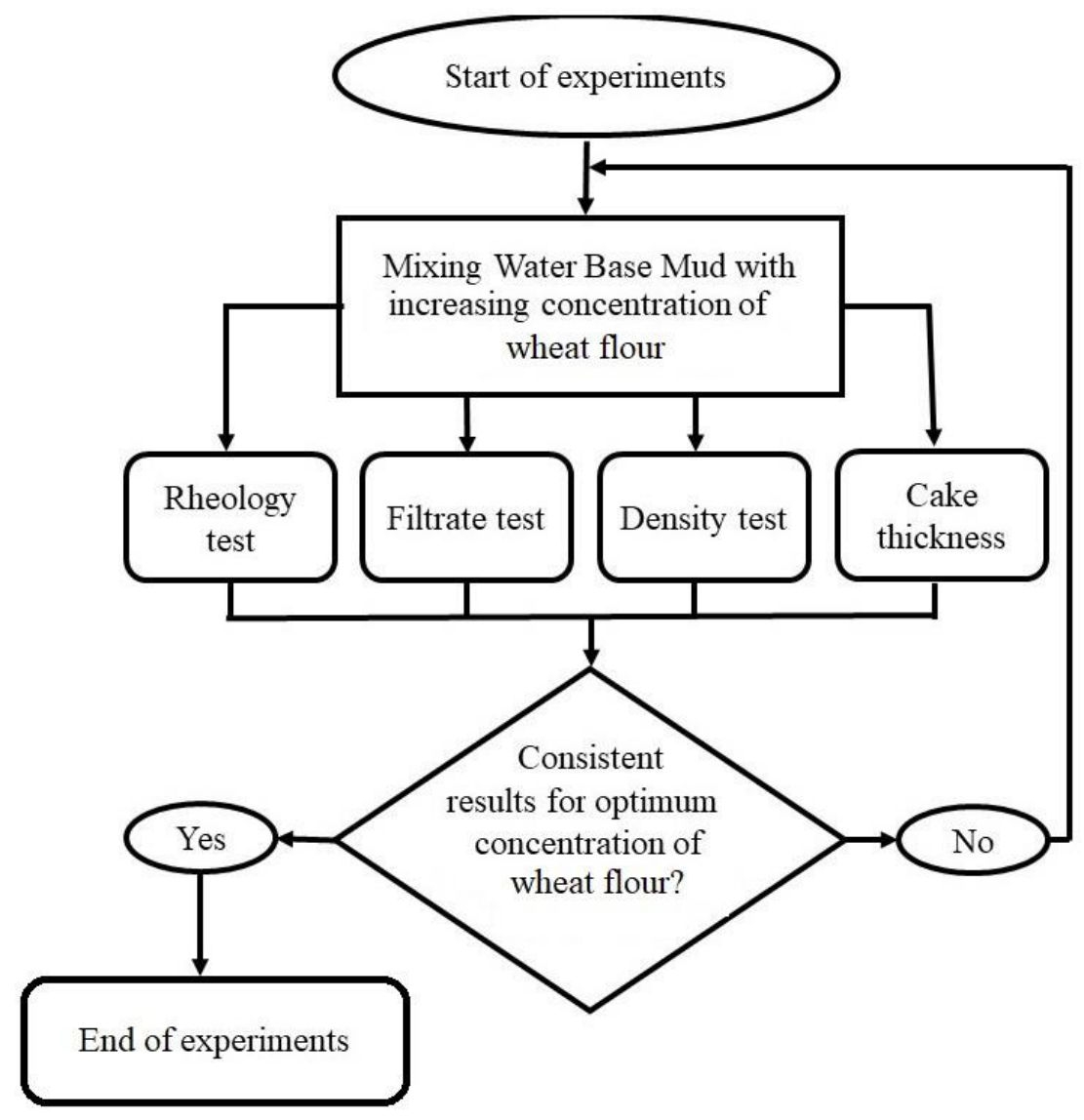

Figure 1. Experimental workflow chart

\subsection{Rheological properties determination}

Experiments were carried out to determine the rheological properties by using a Fann Viscometer (Model $35 \mathrm{SA}$ ) device. These experiments were performed at six different speeds on drilling fluid samples $(600,300,200,100,6$, and 3$) \mathrm{rpm}$ at room temperature. The sample was first poured into the cylindrical cup of the device with an appropriate volume according to the manual of the device, then the cylindrical cup was installed on the device after making sure that the rotor was installed, which must be clean and dry. The readings were recorded at each of the previous speeds, making sure to rotate at 600 rpm for ten seconds when switching between the different speeds to ensure the reliability of the measurement. Calculations of the apparent viscosity, plastic viscosity, and gel strength were performed using the following equations:

$$
\begin{aligned}
& A V=\theta 600 / 2 \\
& P V=\theta 600-\theta 300 \\
& Y P=\theta 300-P V
\end{aligned}
$$


Where

- AV is apparent viscosity $(\mathrm{cP})$

- PV is Plastic viscosity $(\mathrm{cP})$

- YP is Yield point $\quad\left(\mathrm{lb} / 100 \mathrm{ft}^{2}\right)$

- $\Theta 600$ is dial reading at $600 \mathrm{rpm}$

- $\Theta 300$ is dial reading at $300 \mathrm{rpm}$.

For gel strength was measured by rotating the sample at $600 \mathrm{rpm}$ for ten seconds, then turning off the device for ten seconds, and finally turning on the device at $3 \mathrm{rpm}$ and recording the maximum reading that the device dial reaches by $\mathrm{lbs} / 100 \mathrm{ft}^{2}$ unit. Then the process was repeated when the device was turned off for a minute and ten minutes.

\subsection{Density determination}

Experiments were carried out to determine the density by using the Model 140 Fann Mud Balance device. The device cup was filled with the sample, then closed cup by device cover and clean cup from the outside. Finally, the cup was placed on the device holder and try to achieve a balance between the device cup filled with the drilling fluid sample and the slider on the arm of the device by trying to place the bubble between the two lines and recording the density reading in lb/gal unit.

\subsection{Determination of fluid loss}

Experiments were carried out to determine the fluid loss by using an API LT-LP filtration device at 100 psi pressure and room temperature. The measuring was carried out for 30 minutes. The device cell was filled with the drilling fluid sample, the filter paper was placed, and the cell was tightly closed. After installing the cell on the device holder, a pressure of 100 psi was applied to the cell, which was provided by a nitrogen gas cylinder. The filtrate was collected by a graduated cylinder and a reading of the filtrate volume was recorded in ml unit at different times $(1,3,5,7.5,10,15,20,25$, and 30) minutes. Then the filter paper was removed, and the thickness of the mud cake was measured three times and record the average thickness in mm unit.

\section{Results and discussion}

\subsection{Drilling fluid rheology determination}

Figure 2 shows the apparent and plastic viscosity values and gel strength of the drilling fluid depending on the percentage of wheat flour. drilling fluid rheology is useful to determine the capability of the drilling fluid to remove the cutting from the bottom of the hole to the surface and the capability to clean the hole during the drilling operation. As can be seen in Figure 2, the plastic and apparent viscosity increase with increasing the percentage of wheat flour. But for yield point, can be noticed that its value decreases from $15 \mathrm{lb} / 100 \mathrm{ft}^{2}$ to $13 \mathrm{lb} / 100 \mathrm{ft}^{2}$ when $1 \mathrm{wt} \%$ of wheat flour was added, but adding higher than $1 \mathrm{wt} \%$ of wheat flour, it can be noticed increasing in yield point values to reach $23 \mathrm{lb} / 100 \mathrm{ft}^{2}$ at 7 wt $\%$ of wheat flour. Experiments have shown that the plastic viscosity values range between 5 and 13 $\mathrm{cp}$, which means that using small proportions of wheat flour can improve the viscosity significantly thus increases the effectiveness of cleaning the hole and reduce several drilling problems such as high torque and pipe sticking. 


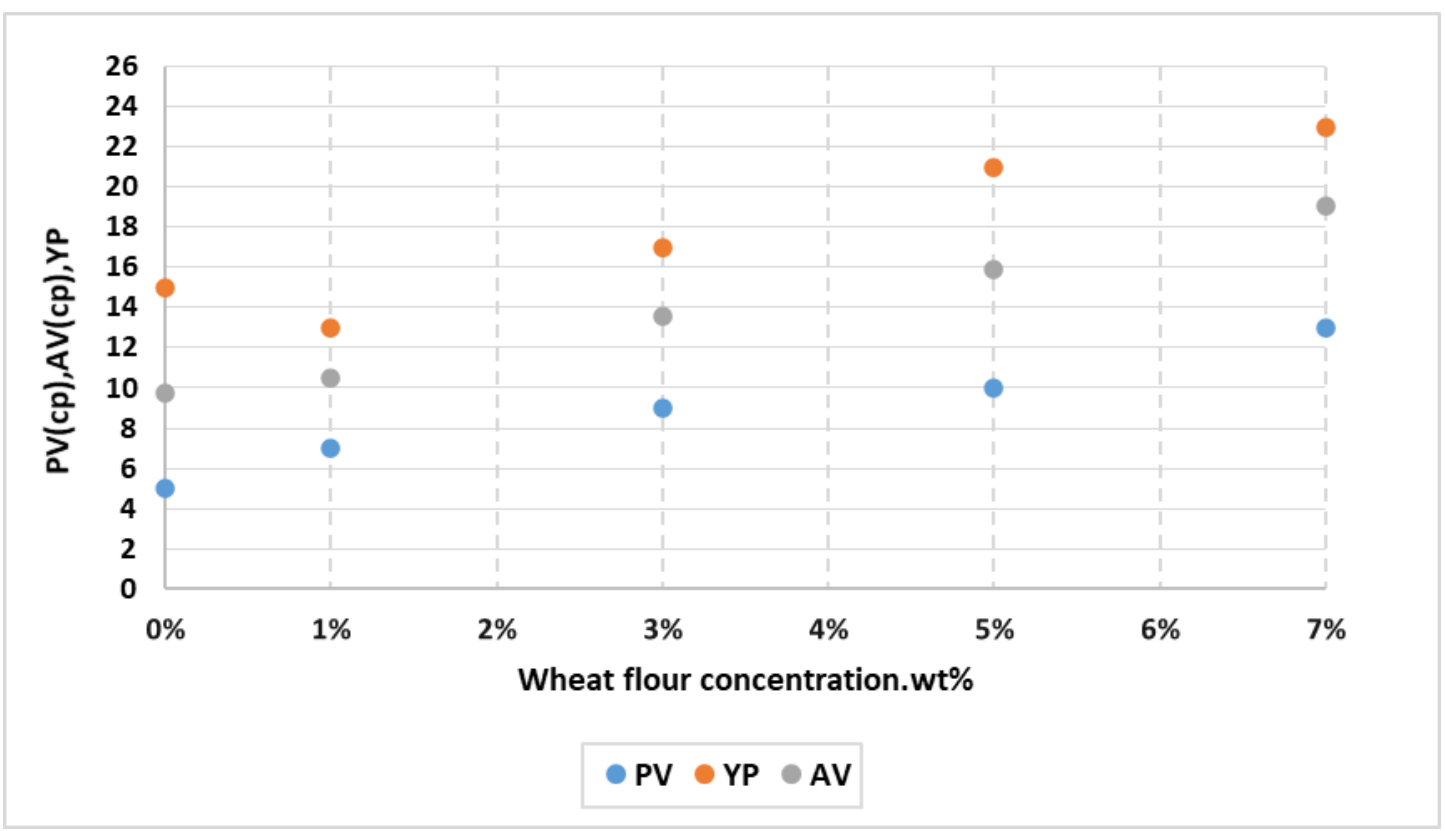

Figure 2. Mud rheology for mud samples

The result of the increased concentration of wheat flour on the gel strength of the drilling fluid is shown in Figure 3. It can be noticed that the gel strength increases from $27 \mathrm{lb} / 100 \mathrm{ft}^{2}$ to $44 \mathrm{lb} / 100 \mathrm{ft}^{2}$ at 7 wt $\%$ of wheat flour, which means using wheat flour in drilling fluid improves the carriage capacity of the cuttings. Keeps the cuttings in suspension which is necessary when drilling is stopped for a long time for maintenance purposes and reduces the pressure value which is required to recycle the drilling fluid again.

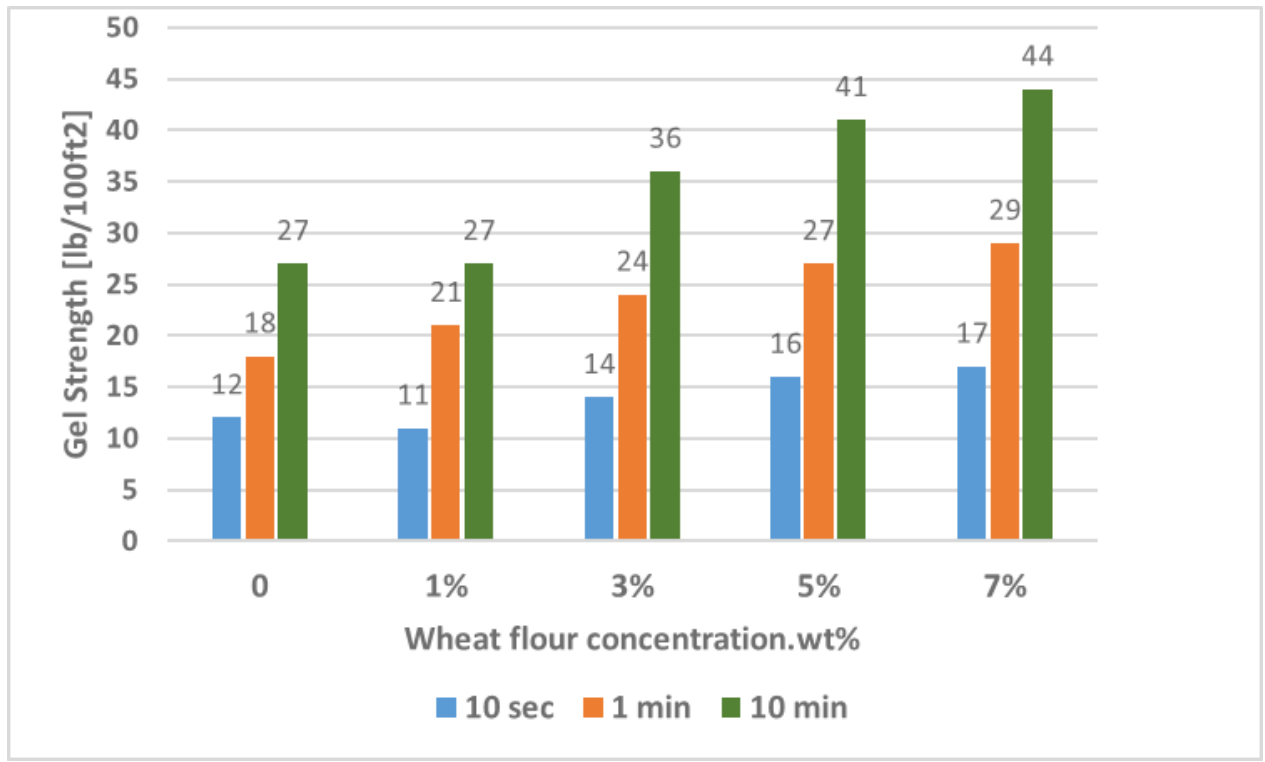

Figure 3. The gel strength of mud samples 
Figure 4 represents higher shear rates obtained for samples with $7 \mathrm{wt} \%$. An increase in wheat flour concentration led to increasing shear stress required to circulate the drilling fluid in the annulus. Figure 4 shows the high shear stress is provided by the low concentration of wheat flour. From analysing the results of the rheological test, it was found that increasing the concentration of wheat flour in the drilling fluid greatly improved the viscosity.

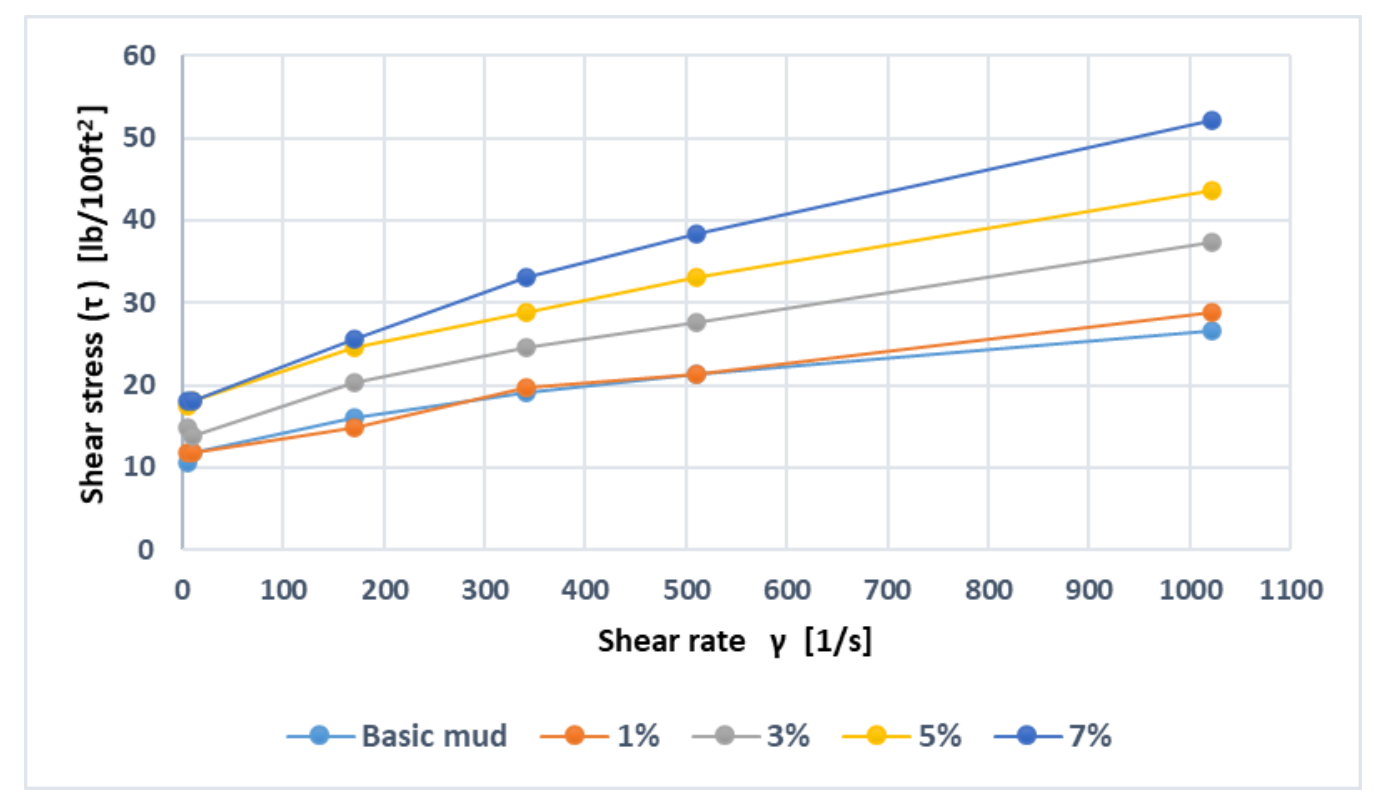

Figure 4. Shear stress vs shear rate for mud samples

\subsection{Density determination}

From Figure 5 it can be noticed that the density of the reference drilling fluid is $8.61 \mathrm{lb} / \mathrm{gal}$, with the increase of the percentage of wheat flour to the drilling fluid the density value increases to $8.80 \mathrm{lb} / \mathrm{gal}$ at $7 \mathrm{wt} \%$. The addition of a slight amount of wheat flour can provide the desired density and that can reduce the amount of barite used to achieve the desired density increase.

\subsection{Fluid loss determination}

By using the API LT-LP filter device the fluid loss test on all studied samples was performed under room temperature conditions. Figure 6 , shows that the volume of fluid loss in the reference drilling fluid was $19.2 \mathrm{ml}$, with the increase in the concentration of the wheat flour in the drilling fluid the volume of the fluid loss decreases to $18.8 \mathrm{ml}$ at $1 \mathrm{wt} \%$, to $16.6 \mathrm{ml}$ at $3 \mathrm{wt} \%$ and the minimum value for the fluid loss volume was $14.4 \mathrm{ml}$ at $7 \mathrm{wt} \%$.It is obvious that the optimum concentration in this test is $7 \mathrm{wt} \%$ of the wheat flour which provides a minimum volume of fluid loss and consequently reduces the problems of contamination of formations by drilling fluid as a result maintains the productivity of that formation. The wheat flour reduces the permeability of the filter cake which helps to reduce the infiltration of drilling fluid inside the formations. 


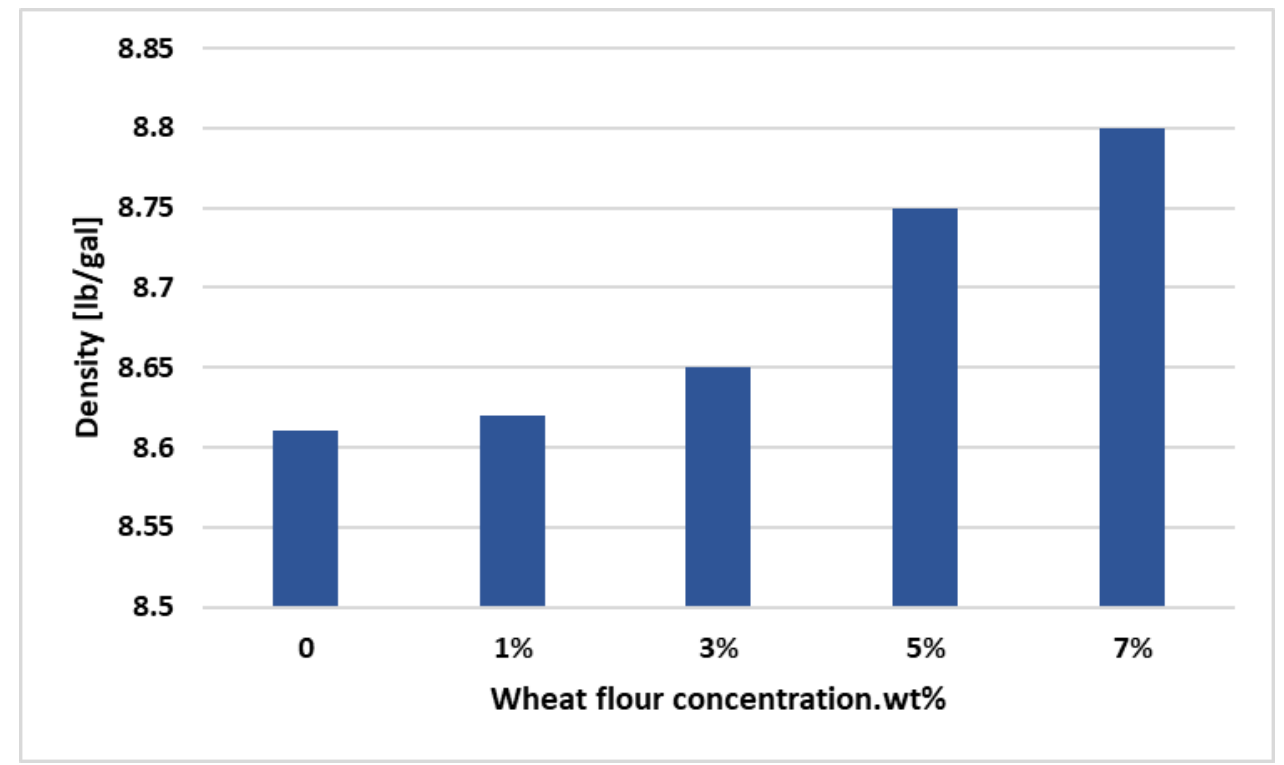

Figure 5. Mud density of the samples

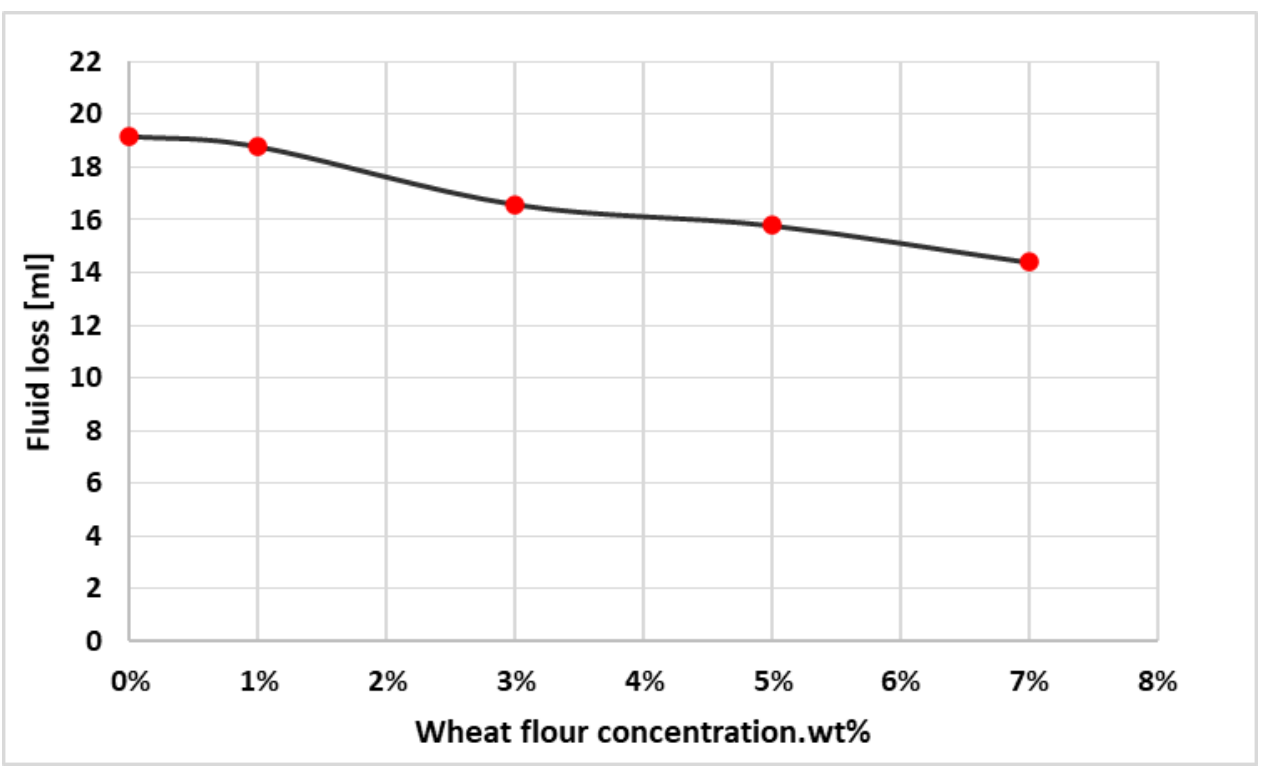

Figure 6. The fluid loss for mud samples

Figure 7 shows that the cake thickness decreases from $2 \mathrm{~mm}$ to $1.8 \mathrm{~mm}$ at $1 \mathrm{wt} \%$ and $3 \mathrm{wt} \%$. The thickness of the cake increases with further increase in concentration to $1.9 \mathrm{~mm}$ at $5 \mathrm{wt} \%$, to $2 \mathrm{~mm}$ at 7 wt $\%$. However, the filter cake did not exceed the size of the base mud even with the highest concentration in this test. 


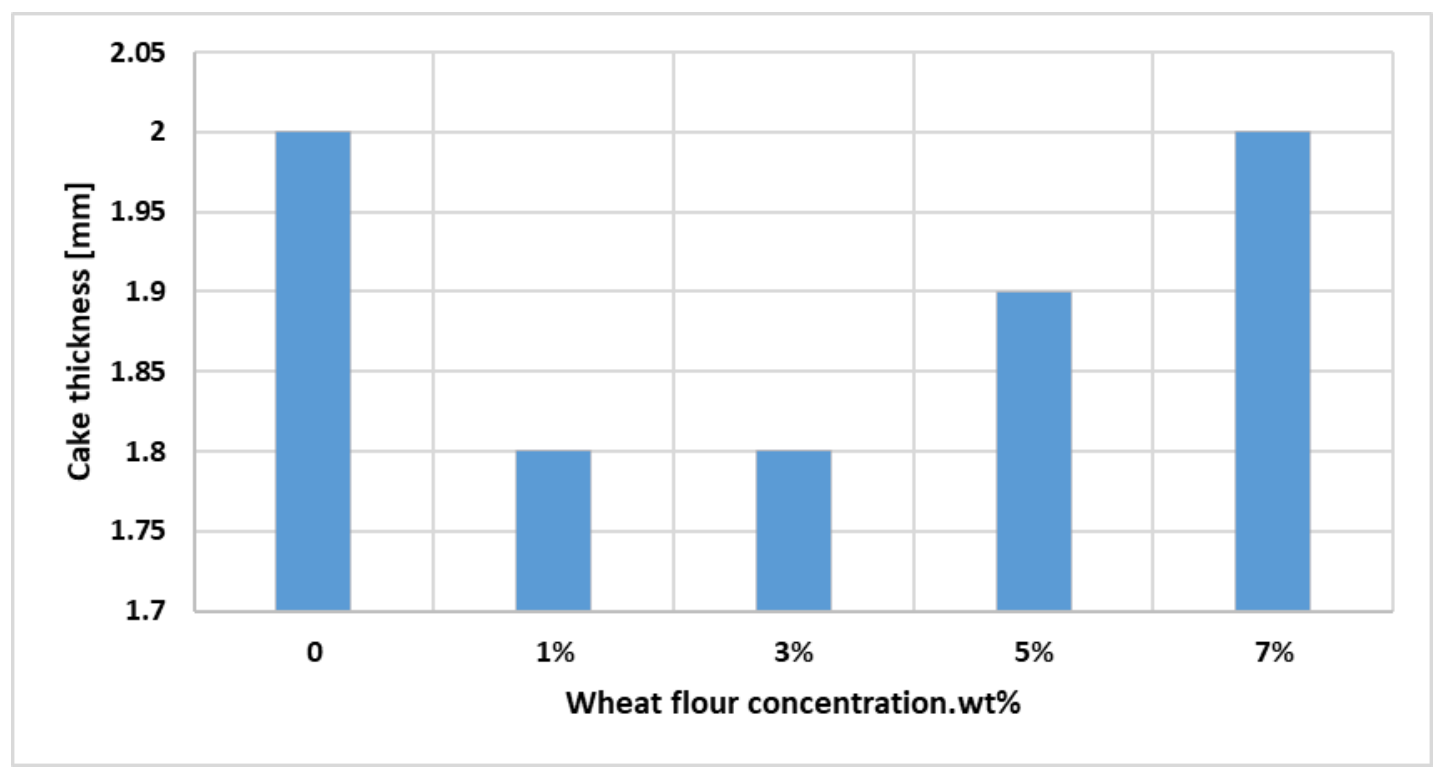

Figure 7. Cake thickness for mud samples

\section{Summary and Recommendations}

In this study, the effect of wheat flour on water-based mud samples was studied based on experimental tests in the drilling lab. The properties of the drilling fluid samples were determined through various tests such as rheology, density, fluid loss and cake thickness based on American Petroleum Institute standards. The addition of wheat flour to the drilling fluid enhances the rheology of the water-based drilling fluid. So, the optimum concentration that showed the greatest enhancement in this index test was at $7 \mathrm{wt} \%$ of wheat flour. The addition of wheat flour reduces fluid loss by $25 \%$ at $7 \mathrm{wt} \%$. The improvement of rheological properties led to the effectiveness of cleaning the borehole, reduced various problems such as high torque, pipe sticking and reduced the total drilling time.

Based on the results of this test it can be seen that the increasing concentration of wheat flour changes the rheological parameters in a consistent manner. Therefore, it is easy to regulate the necessary properties of the drilling fluid with wheat flour as an additive to the required values.

To improve this study several points can be taken into consideration. First, the water-based mud system can be used by adding CMC and XG. Also, the effect of wheat flour at different temperatures can be tested for drilling fluid samples. Finally, the study of the chemical interaction between wheat flour and drilling fluids could help to improve the properties of water-based drilling fluids. The concentrations in this paper's experiments ranged from 0 to $7 \mathrm{wt} \%$, and we recommend that in future studies, the concentrations be increased to more than $7 \mathrm{wt} \%$.

\section{Acknowledgements}

The research was carried out at the University of Miskolc both as part of the project implemented in the framework of the Thematic Excellence Program funded by the Ministry of Innovation and Technology of Hungary (Grant Contract reg. nr.: NKFIH-846- 8/2019) and the project supported by the Ministry of Innovation and Technology of Hungary from the National Research, Development and Innovation Fund 
in line with the Grant Contract issued by the National Research, Development and Innovation Office (Grant Contract reg. nr.: TKP-17-1/PALY-2020).

\section{References}

[1] R. H. (2001). Well Engineering \& Construction. Entrac Consulting, ISBN-10: 0954108701

[2] Amanullah, M.: Screening and evaluation of some environment-friendly mud additives to use in water-based drilling muds. 2007 SPE E\&P Environmental and Safety Conference, Galveston, Texas, USA https://doi.org/10.2118/98054-MS

[3] Biltayib, B. M., Rashidi, M., Balhasan, S., Alothman, R., Kabuli, M. S. (2018). Experimental analysis on rheological and fluid loss control of water-based mud using new additives. Journal of Petroleum and Gas Engineering, 23-31. https://doi.org/10.5897/JPGE2017.0279

[4] Amanullah, M., Marsden, J., Shaw, H. (1997). An experimental study of swelling behaviour of mudrocks in present of drilling mud systems. Canadian Journal of Petroleum Tech., 36(3), 4550. https://doi.org/10.2118/97-03-04

[5] Iqbal, R., Pirzada, F., Zubair, M., Mehmood, A. (2020). An experimental study on performace of starch extracted from wheat flour as filtration control agent in drilling fluid. International Journal of Advances in Applied Sciences (IJAAS), 255-260. https://doi.org/10.11591/ijaas.v9.i4.pp255-260

[6] Blazek, J., Copeland, L. (2007). Pasting and swelling properties of wheat flour and starch in relation to amylose content. Carbohydrate Polymers, 380-387. https://doi.org/10.1016/j.carbpol.2007.06.010

[7] Hudson, T., Coffey, M., Sauer, J. C. W., Teot, A. (1983). Fluid-loss control through the use of a liquid-thickened completion and workover brine. Journal of Petroleum Technology, 35(10), 1776-1782. https://doi.org/10.2118/10652-PA

[8] Ghazali, N., Alias, N., Mohd, T., Adeib, S., N. M.Y. (2015). Potential of corn starch as fluid loss control agent in drilling mud. Applied Mechanics and Materials, 2754-755, 682-687. https://doi.org/10.4028/www.scientific.net/AMM.754-755.682

[9] Mojeed, O., Yetunde, A., Segun, A., Atanda, B. (2019). Evaluation of the Potential of Cassava Flour as Viscosifier in water-Based Mud. International Journal of Science and Research (IJSR), 9(8), 420-423. 